\title{
Slice and excise technique in hysterscopic myomectomy for large g0 submucous myoma
}

\begin{abstract}
Background: 'Resectoscopic slicing' still represents the 'gold standard' technique for treating submucous fibroids totally intra-cavitary G0. The main limiting factor for surgery completion is the risk of fluid overload, which may necessitate surgery cessation. In the presence of large sized G0 myoma, in the absence of morcellator, a second operation may be a must.
\end{abstract}

Aim: The aim of this study is to compare between the (conventional resectoscopic slicing) technique and (slicing and excising technique) in hysteroacopic management of large G0 myomas.

Materials and methods: A prospective case-control study, conducted in tertiary hospital was done. 36 women aged between 23-45 years with G0 myomas, with bleeding or infertility problems were included in the study. The patients were randomized into two groups: 17 women in which (conventional resectoscopic slicing) was done and 19 women in which (slicing and excising technique) was done.

Results: Conventional slicing technique had longer operative time than slice and excise technique with a statistically significant difference $\mathrm{p}<0.05$. In $3 / 17(17.6 \%)$ of conventional slicing technique, incomplete surgery with a second session was needed. In one case of slice and excise technique 1/19 (5\%), complete myomectomy wasn't achieved in one session. Operative time was significantly shorter in slice and excise technique $(p<0.05)$. Fluid deficit was more in conventional than slice and excise group, but with no statistic significant difference. No intraoperative complications occurred in either group.

Conclusion: In the presence of large G0 myomas 4-5 cm, and the absence of hysteroscopic morcellator, the technique (slice and excise) is as effective as conventional slicing with less operative time, less fluid deficit and more reliable for completion of surgery in one session.

Keywords: G0 myomas, Hysteroscopic slicing, Fluid deficit, Completion of myomectomy, Slice and excise
Volume 7 Issue 4 - 2017

Sally Sayed EI Tawab

Obstetrics \& Gynecology department, Shatby Maternity University Hospital, Egypt

Correspondence: Sally Sayed El Tawab, Lecturer of Obstetrics \& Gynecology, Obstetrics \& Gynecology department, Shatby Maternity University Hospital, Faculty of Medicine, Alexandria University, Egypt, Email sally_eltawab@hotmail.com

Received: January 29, 2017 | Published: August 02, 2017

\section{Introduction}

'Resectoscopic slicing' still represents the 'gold standard' technique for treating submucous fibroids totally intra-cavitary G0, even if several other effective techniques including laser ablation, morcellation and office myomectomy have been proposed. Hysteroscopic procedures are often considered minimally invasive, but complications occasionally occur. ${ }^{1}$ Hysteroscopic myomectomy is one of the most advanced hysterscopic procedures and is associated with a significantly higher rate of complications, particularly in complex cases. ${ }^{2,3}$ Complication rates have ranged from $0.3 \%$ to $28 \%$, and fluid overload and uterine perforation are the most frequent complications during surgery. Other complications include bleeding, cervical trauma, and air embolism; late complications include postoperative intrauterine adhesion. ${ }^{4}$

The most dangerous complication is an excessive intravasation of the fluid used to distend and irrigate the uterine cavity, with resultant fluid overload. This fluid overload and resultant toxicity syndrome is called Operative Hysteroscopy Intravascular Absorption syndrome (OHIA) syndrome. ${ }^{5}$ Also, known as the Gynecological TURP

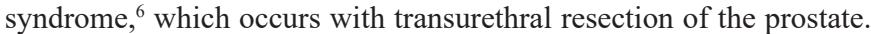
Management of this risk relies on close monitoring of the fluid balance and interruption of the procedure prior to excessive fluid absorption occurring, ${ }^{7,8}$ making it the most feared, lethal and at the same time; the most easily avoided complication. However, conventional monopolar resectoscope mandates the use of an electrolyte-free, lowviscosity solution (for example, $1.5 \%$ glycine, $3 \% \mathrm{D}$-sorbitol, and $5 \%$ mannitol). These solutions, if absorbed in excessive amounts, lead to fluid-overload hyponatremia, encephalopathy, cardiac failure, generalized tissue odema, pontine herniation and respiratory center death. Glycine has additional disadvantages, it is metabolized to ammonia by the liver, which is liposoluble and cross the blood brain barrier, being metabolized to serine and glyoxylic acid, which are false neurotransmitters. ${ }^{9}$ Long-term morbidity and even death have been reported, making prevention of this fluid overload critical. ${ }^{10}$ The syndrome usually manifest 30-45 min after completion of surgery. It was suggested that regional anaesthesia might be advantageous as the awake patient is more likely to display precursor symptoms e.g. prickling sensation in face and neck, visual disturbances. During general anaesthesia, it was advisable to adhere to repeated blood sampling for serum sodium concentration as a method of monitoring. ${ }^{11}$ Although electrolyte containing solutions e.g. normal saline or Ringer's lactate used with bipolar resectoscope increase the margin of safety and eliminate the risk of hypo-osmolarity and hyponatraemia, the risk of fluid overload and pulmonary odema is still present. ${ }^{12}$

There are three factors that significantly determine the feasibility of hysteroscopic myomectomy, the degree of intramural extension, the myoma size and the myoma consistency. ${ }^{13}$ A study stated that patients with myomas larger than $5 \mathrm{~cm}$ or with a Lasmar score higher than 7 were more likely to undergo a 2 -step procedure. ${ }^{14}$ 
One -step myomectomy remains more desirable and (cold loop myomectomy) might be a good option for safe and effective removal in one surgical setting. ${ }^{15}$ In this technique, the intracavitary portion of the myoma is removed by slicing using monopolar electrode. Then, the loop is replaced with a cold loop (mechanical loops of Mazzon; Karl Storz, Tuttlingen; Germany), which is inserted into the cleavage plane along the myoma surface to disconnect it by blunt dissection. Finally, after detachment, the intramural part becomes intracavitary and removed by slicing. ${ }^{16}$

Moreover, intrauterine hysteroscopic morcellators were also proposed to address these limitations and have been successfully used to remove submucosal leiomyomas. ${ }^{17}$ But even with morcellator usage, a recently published study concluded that when multivariable logistic regression analysis was performed for possible factors associated with incomplete resection of a leiomyoma, including total size of pathology, size of the largest leiomyoma, operator skill level, and subtype of leiomyoma $(0,1$, or 2$)$. The size of the largest leiomyoma $(\mathrm{p}<0.005)$ and the seniority of the surgeon $(\mathrm{p}<0.012)$ were the only significant factors associated with the likelihood of complete resection with a single procedure [18]. In many centers, morcellator is still not available, dealing with large myomas are still challenging to be completed in one session, even in type 0 submucous myomas.

\section{Objective}

The aim of this study is to compare between the conventional resectoscopic slicing technique and slice and excise technique in hysteroscopic management of large G0 myomas.

\section{Patients and methods}

A prospective case-control study, conducted in Shatby Maternity University Hospital in period from August 2014 till September 2016, was done. The study was conducted after the approval of Ethical Committee of Alexandria University, Faculty of Medicine. Thirty-six women aged between 23-45 years with G0 myomas, with bleeding or infertility problems were included in the study, after a comprehensive written consent. All women had 3D ultrasound to confirm the diagnosis of grade 0 submucous myoma (in which no mural extension existed), and confirm the size and site. Only large myomas with diameter $4-5 \mathrm{~cm}$ were included. Exclusion criteria were severe anemia $($ Hemoglobin $<9 \mathrm{gm} / \mathrm{dl})$, lower genitourinary tract infection, premalignant lesions of the uterine cavity diagnosed by a prior endometrial biopsy, cancer cervix and the presence of more than one submucous myoma.

The selected patients were randomized preoperatively using a computer-generated randomization sheet into two group. Group allocation was concealed in an opaque envelope, which was opened at the time of each woman's procedure. 17women in which (conventional resectoscopic slicing) was done and 19 women in which (slicing and excising technique) was done.

\section{Conventional resectoscopic slicing technique: women)}

Myoma was sliced starting from the dome gradually in chips until the myoma base was achieved, with intermittent cavity evacuation from the accumulating chips.

\section{Slicing and Excising technique: (I 7 women)}

The same as the conventional technique, stating from the myoma dome and approaching toward its base, with circumferentially slicing along the myoma sides till the myoma size is much smaller in an oblong shape, when it could be adequately and blindly grasped by a small ring forceps (Figure 1, the smaller forceps to which the arrow point). This particular forceps size allows its introduction through the dilated cervix till Hegar 10. Then the grasped oblong remaining myomais twisted gently and repeatedly in one direction together with gentle force, until the myoma is excised and removed (Figure 2). The hysteroscope is reintroduced to evaluate the myoma bed, any myoma remnants are sliced and removed, and any bleeding points are coagulated. The technique is finished once the myometrium fasciculate is visualized.

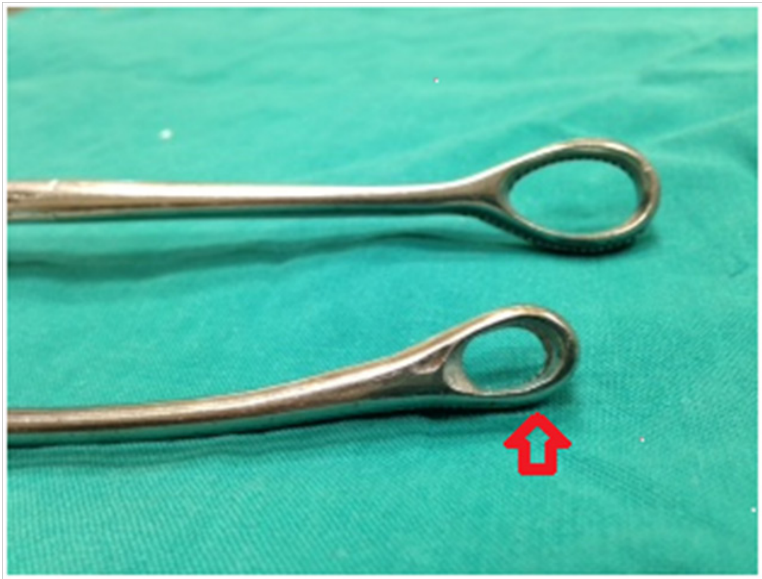

Figure I The forceps used to grasp and excise.

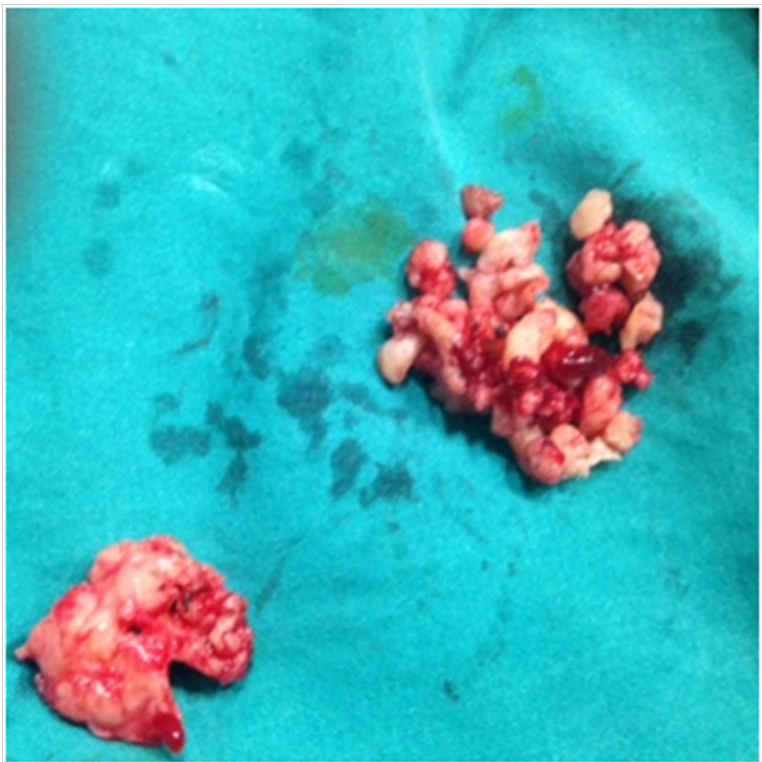

Figure 2 Chips sliced from the myoma and the part of myoma excised.

\section{Each procedure using either technique was described as regards}

Operative time defined as the interval between initial insertion and final removal of the instrument.

Fluid deficit was calculated as the difference between total amount of glycerine instilled into the uterus and the amount of fluid removed from the suction bottle used and the plastic drapping that funneled the escaping fluid through the cervix into the calibrated pouch. Any 
operative complications e.g. perforation, hemorrhage, thermal injury, or fluid overload. Completion of the myoma resection. Post-operative hemorrhage, infection, and pain.

An informed consent was obtained from all patients preoperatively, including consent of being included in the study, details of the procedure, possible complications and the potential need for a second procedure to complete the resection if needed. The operations were done in the immediate post-menstrual period.

General anaesthesia with endotracheal intubation was used for all patients. Monopolar resectoscope was used with glycine as the distending medium. The fluid balance was monitored carefully, fluid deficit of $1 \mathrm{~L}$ was an alarm for the surgeon to terminate the procedure within few minutes.

\section{Results}

The age ranged 23-45 for all women included in the study, with no statistic significant difference between women undergoing either technique as seen in (Table 1). Heavy menstrual bleeding was the main complaint in both groups. The operative time was statistically shorter in slice and excise technique compared to the conventional slicing technique $(\mathrm{p}<0.05)$ (Table 2$)$. The range of fluid deficit reached the maximal level allowed with glycine instillation, which is $1000 \mathrm{ml}$, in 3 cases in conventional slicing group, necessitating the stoppage of surgery and another session was needed. The fluid deficit was less in slice and excise technique, but didn't reach the level of statistical significance (Table 2). No intra-operative complications occurred in either group.

Table I Demographic data of patients in both groups

\begin{tabular}{llll}
\hline & $\begin{array}{l}\text { Conventional resectoscopic } \\
\text { technique }(\mathbf{n o = 1 7 )}\end{array}$ & $\begin{array}{l}\text { Slice and excise } \\
\text { technique (no=19) }\end{array}$ & $\begin{array}{l}\text { Test of } \\
\text { significance }\end{array}$ \\
\hline $\begin{array}{l}\text { Age } \\
\text { Range }\end{array}$ & $23-43$ & $24-45$ & $\mathrm{t}=0.69$ \\
$\begin{array}{l}\text { Mean } \pm \text { SD } \\
\text { Gravidity }\end{array}$ & $31.64 \pm 6.49$ & $33.1 \pm 6.35$ & \\
Range & $0-4$ & $0-5$ & $\mathrm{t}=0.59$ \\
Mean \pm SD & $1.82 \pm 1.59$ & $1.47 \pm 1.46$ & \\
Parity & & & $\mathrm{t}=0.47$ \\
Range & $0-4$ & $0-5$ & \\
$\begin{array}{l}\text { Mean } \pm \text { SD } \\
\text { Complaint }\end{array}$ & $1.7 \pm 1.57$ & $1.36 \pm 1.42$ & $\mathrm{NS}$ \\
$\begin{array}{l}\text { Heavy menstrual bleeding } \\
\text { infertility }\end{array}$ & $7(41.1 \%)$ & $8(42.1 \%)$ & $7(36.8 \%)$ \\
Recurrent pregnancy loss & $6(35.2 \%)$ & $4(21 \%)$ & \\
\hline
\end{tabular}

NS: Non-Significant.

Table 2 Operative time and fluid deficit in both groups

\begin{tabular}{llll}
\hline & $\begin{array}{l}\text { Conventional resectoscopic } \\
\text { technique }(\mathbf{n o = 1 7 )}\end{array}$ & $\begin{array}{l}\text { Slice and excise } \\
\text { technique }(\mathbf{n o = 1 9 )})\end{array}$ & $\begin{array}{l}\text { Test of } \\
\text { significance }\end{array}$ \\
\hline $\begin{array}{l}\text { Myoma Size } \\
\text { Range } \\
\text { mean } \pm \text { SD }\end{array}$ & $4-5 \mathrm{~cm}$ & $4-5 \mathrm{~cm}$ & $\mathrm{NS}$ \\
$\begin{array}{l}\text { Operative time }(\mathbf{m i n}) \\
\text { Range }\end{array}$ & $4.48 \pm 0.33$ & $4.47 \pm 0.35$ & \\
mean \pm SD & $55-80$ & $50-75$ & $\mathrm{t}=1.5$ \\
$\begin{array}{l}\text { Fluid deficit (ml) } \\
\text { Range }\end{array}$ & $65.58 \pm 9.5$ & $60.82 \pm 7.3$ & $\mathrm{p}<0.05 *$ \\
mean \pm SD & $600-1000$ & $580-1000$ & $\mathrm{t}=0.66$ \\
\hline
\end{tabular}

NS: Non-significant.

Table 3 Completion of surgery

\begin{tabular}{lll}
\hline & $\begin{array}{l}\text { Conventional resectoscopic } \\
\text { technique }(\text { no= 17) }\end{array}$ & $\begin{array}{l}\text { Slice and excise } \\
\text { technique }(\text { no=19) }\end{array}$ \\
\hline Incomplete surgery & $3(17.6 \%)$ & $1(5.2 \%)$ \\
\hline
\end{tabular}

\section{Discussion}

The classical hysteroscopic excision of Go fibroid is carried out with the technique of slicing. It consists of repeated and progressive passages of the cutting loop starting from the top of the myoma, progressing in a uniform way towards the base. ${ }^{19,20}$ The myoma size remains the most important factor determining the likelihood of completing the hysteroscopic resection in one setting. Increasing leiomyoma size was negatively correlated with complete removal. ${ }^{21,22}$ Several methods and techniques were published trying to increase the possibility of one session removal. Studies suggested the use of preoperative medical treatment with gonadotropin-releasing hormone $(\mathrm{GnRH})$ agonists in facilitating surgery and improving the long-term result of hysteroscopic myomectomy. Another study 
suggested multiple slicing sessions technique with hydromassage. ${ }^{23}$ Also, laser usage was suggested, in which the fibroid was first cut into pieces until the residual fibroids could be extracted by forceps. ${ }^{24}$ In addition, using transvaginal radiofrequency myolysis with or without hysteroscopy was tried. ${ }^{25}$ Moreover, intralesional vasopressin injection was also described. ${ }^{26}$ Modified technique in which the base was excised followed by ring forceps extraction after misopristol priming. ${ }^{27}$ Morcellators, with no doubt shorten the operative time and fluid deficit, ${ }^{28}$ but they can't yet concurrence the hysteroscopic resectoscopes for the treatment of large submucous myomas or those with a large intramyometrial involvement. ${ }^{29}$ In more detailed very recent analysis of hysteroscopic morcellator in submucous myomas, it was stated that complete resection was achieved in $90 \%$ of leiomyomas $<20 \mathrm{~mm}$, in $89 \%$ of those 20 to $29 \mathrm{~mm}$, in $83 \%$ of those 30 to $39 \mathrm{~mm}$, and in $48 \%$ of those $>40 \mathrm{~mm}$. Leiomyomas were completely resected in 63 of 95 cases $(66 \%)$. For those with incomplete resection in which $50 \%$ of pathology resected were $>40 \mathrm{~mm}$ in size. ${ }^{18}$

The size greater than $4 \mathrm{~cm}$ remains challenging irrespective to the grade. In this study, only large size $4-5 \mathrm{~cm}$ grade 0 totally intracavitary myomas were included, eliminating the added difficulty of intramural extension of the myoma.

A similar technique was described when approaching Go myomas, through cutting the base of the pedicle by a resectoscopic loop ${ }^{30}$ or by a vaporizing electrode. The myomas is grasped blindly by the forceps and extracted. If the myoma is large, as the cases in our study, it might be difficult to grasp it and in such situation it was suggested to be left in place until it is excreted spontaneously during the first mensis after surgery. The main drawback of this technique is the continuous colicky pain and the risk of intra-uterine infection. ${ }^{27}$

The solitary factor necessitating the stoppage of hysteroscopic procedures at once in the absence of complications e.g. hemorrhage or perforation, is reaching the set maximal fluid deficit. So, once the anesthetist or the fluid monitoring staff warned for reaching the maximal fluid deficit allowed, the surgeon has to stop the procedure at once. In this study, the maximal fluid deficit set at $1 \mathrm{~L}$ was reached in 4 cases in both groups. In one of the four cases, with conventional technique, the myoma was completely resected at that point and no further resection was needed. While with the other 3 cases, stoppage of surgery and need of another setting was mandatory. On the other hand, with slice and excise technique, in 3 of 4 cases, the myoma residual at that time has reached a size and shape making it feasible for ring forceps grasping, torsion and gentle traction, with complete excision, with no further surgery needed. Only in one case, the myoma residual was still large, necessitating stoppage of surgery and second session.

In our study, operative time was statistically shorter with slice and excise technique than conventional slicing technique $(p<0.05)$, the fluid deficit was less with slice and excise technique but didn't reach the level of statistical significance.

The main limitation in our study was the same number of cases. Nevertheless, large Go myomas are relatively rare and to obtain sufficient number of such fibroids a long observation time could be necessary.

\section{Conclusion}

In the presence of large G0 myomas $4-5 \mathrm{~cm}$, and the absence of hysteroscopic morcellator, the technique (slice and excise) is as effective as conventional slicing with less operative time, less fluid deficit and more reliable for completion of surgery in one session.

\section{Acknowledgments}

None.

\section{Conflicts of Interest}

The author has no conflict of interest to declare.

\section{References}

1. Chang CY, Chang YT, Chien SC, et al. Factors associated with operative hysteroscopy outcome in patients with uterine adhesions or submucosal myomas. Int J Gynaecol Obstet. 2010;109(2):125-127.

2. Kang FW, Yang HC, Chen MJ, et al. One-step hysteroscopic removal of large sinking submucous myoma. Taiwan J Obstet Gynecol. 2008;47(2):238-240.

3. Murakami T, Hayasaka S, Terada Y, et al. Predicting outcome of onestep total hysteroscopic resection of sessile submucous myoma. J Minim Invasive Gynecol. 2008;15(1):74-77.

4. Sardo AD, Mazzon I, Bramante S, et al. Hysteroscopic myomectomy: a comprehensive review of surgical techniques. Hum Reprod Update. 2008;14(2):101-119.

5. Jackson $\mathrm{S}$, Lampe G. Operative hysteroscopy intravascular absorption (OHIA) syndrome. West J Med. 1995;162(1):53-54.

6. Serocki G, Hanss, R, Bauer M, et al. The gynecological TURP syndrome: severe hyponatrameia and pulmonary odema during hysteroscopy. Anaesthesist. 2009;58(1):30-34.

7. Bradely LD. Complications of hysteroscopy: prevention, treatment, and legal risk. Curr Opin Obstet Gynecol. 2002;14(4):409-415.

8. Swedarsky LM, Isaacson K. Complications related to hysteroscopic distension media. In: Isaacson K (Ed.), Complications of gynecologic endoscopic surgery, Philadelphia, WB Saunders, USA. 2006; pp.201207

9. Baumann R, Magos AL, Kay JD, et al. Absorption of glycine irrigating solution during transcervical resection of the endometrium. BMJ. 1990;300(6720):304-305.

10. Loffer FD, Bradley LD, Brill AI, et al. Hysteroscopic fluid monitoring guidelines: from the Ad Hoc Committee on hysteroscopic fluid guidelines of the American Association of Gynecologic Laparoscopists. J Am Assoc Gynecol Laparosc. 2000;7(1):167-175.

11. Sethi N, Chaturvedi R, Kumar K. Operative hysteroscopy intravascular absorption syndrome: a bolt from the blue. Indian $J$ Anaesth. 2012;56(2):179-182.

12. Vulgaropulas SP, Haley LC, Hulka JF. Intrauterine pressure and fluid absorption during continuous flow hysteroscopy. Am J Obstet Gynecol. 1992;167(2):386-390.

13. Lin BL, Kasuga YF, Matsuoka TF, et al. Unsuccessful hysteroscopic removal of a large calcified submucous myoma. Jap J Obstet Gynecol Endosc. 2010;26(2):422-424.

14. Camanni M, BOnino L, Delpiano EM, et al. Hysteroscopic management of large symptomatic submucous uterine myomas. J Min Invas gynecol. 2010;17(1):59-65

15. Sardo A, Mazzon I, Bramante S, Bettochi S, et al. Hysteroscopy myomectomy: a comprehensive review of surgical techniques. Hum Reprod Update. 2008;14(2):101-119.

16. Mazzon I, Favilli A, Cocco P, et al. Does cold loop hysteroscopy myomectomy reduce intra-uterine adhesions? A retrospective study. Fertil Steril. 2014;101(1):294-298.

17. Hamerlynck TW, Dietz V, Schoot BC. Clinical implementation of the hysteroscopic morcellator for removal of intrauterine myomas and polyps. A retrospective descriptive study. Gynecol Surg. 2011;8(2):193196. 
18. Arnold A, Ketheeswaran A, Bhatti M, et al. A prospective analysis of hysteroscopic morcellation in the management of intrauterine pathologies. JMIG. 2016;23(3):435-441.

19. Isaacson K. Hysteroscopic myomectomy: fertility-preserving yet underutilized. OBG Manag. 2006;15(3):69-83.

20. Indman PD. Hysteroscopic treatment of submucous myomas. Clin Obstet Gynecol. 2006;49(4):811-820.

21. Mazzon I, Favilli A, Grasso M, et al. Predicting success of single step hysteroscopic myomectomy : a single center large cohort study of single myomas. Int J Surg. 2015;22:10-14.

22. Kang FW, Yang HC, Chen MJ, et al. One-step hysteroscopic removal of large sinking submucous myoma. Taiwan J Obstet Gynecol. 2008;47(2):239-240.

23. Zayed M, Fouda U A, Zayed S M, et al. Hysteroscopic myomectomy of large submucous myomas in a 1-step procedure using multiple slicing sessions technique. J Minim Invasive Gynecol. 2015;22(7):1196-1202.

24. Chen CH, Lee WL, Wang I Te, et al. Hysteroscopic myomectomy using a two-micron continuous laser (Revolix). Gynecol Min Invas Therapy. 20132:89-92.
25. Cho HM, Kim MR, Kim JH. Outpatient multimodality management of large submucosal myomas using transvaginal radiofrequency myolysis. J Minim Invasive Gynecol. 2014;21(6):1049-1054.

26. Wong AS, Cheung EC, Leung KT, et al. Transcervical intralesional vasopressin injection in hysteroscopic myomectomy-description of a new technique. J Laparoendosc Adv Surg Tech A. 2013;23(3):258-262.

27. Darwish A. Modified hysteroscopic myomectomy of large submucous fibroids. Gynecol Obstet Invest. 2003;56(4):192-196.

28. Shazly SA, Laughlin-Tammaso SK, Breitkopf DM, et al. Hysteroscopic morcellation versus resection for the treatment of uterine cavity lesions: A systematic review and Meta-analysis. J Minim Invasive Gynecol. 2016;23(6):867-877.

29. Garbin O, Schwartz L. New in hysteroscopy: hysteroscopic morcellators. Gynecol Obstet Fertil. 2014:42(12):872-876.

30. Murakami T, Tamura M, Ozawa Y, et al. Safe techniques in surgery for hysteroscopy myomectomy. J Obstet Gynecol Res. 2005;31(3):216-223. 